\title{
EFEITO DE Botrytis cinerea NA COMPOSIÇÃO DO VINHO GEWÜRZTRAMINER ${ }^{1}$
}

\author{
Julio MENEGUZZO², Luiz Antenor RIZZON,*, Alberto MIELE³, Marco Antônio Záchia AYUB ${ }^{4}$
}

\begin{abstract}
RESUMO
Com o objetivo de estudar o efeito da podridão cinzenta da uva, causada por Botrytis cinerea na composição do vinho Gewürztraminer (Vitis vinifera L.), foram analisados vinhos obtidos a partir de uvas com 0; 2,5; $5 ; 10 ; 15$; e $20 \%$ em peso de podridão cinzenta. O experimento consistiu de seis tratamentos e quatro repetições. As variáveis avaliadas foram densidade, álcool, acidez total e volátil, extrato seco, extrato seco reduzido, açúcares redutores, relação álcool em peso/extrato seco reduzido, cinzas, alcalinidade das cinzas, índice de cor (I 420), polifenóis totais (I 280), N total, glicerol, ácido glicônico, minerais (P, K, Ca, Mg, Na, Mn, Fe, Cu, Zn, Rb, Li), compostos voláteis (etanal, acetato de etila, metanol, 1-propanol, 2-metil-1-propanol, 2-metil-1-butanol e 3-metil-1-butanol). A análise de regressão polinomial que avaliou o efeito da podridão cinzenta da uva na composição físico-química do vinho Gewürztraminer, mostrou que houve efeito linear significativo e positivo em relação à densidade, acidez total e volátil, extrato seco, extrato seco reduzido, açúcares redutores, cinzas, alcalinidade das cinzas, índice de cor (I 420), polifenóis totais (I 280), ácido glicônico, P, K, Ca, Mn, Fe, $\mathrm{Rb}$, etanal e acetato de etila; efeito linear significativo e negativo nas variáveis álcool, relação álcool em peso/extrato seco reduzido, 2-metil-1-butanol e 3-metil-1-butanol; efeito quadrático sobre $\mathrm{N}$ total, glicerol e metanol; e efeito cúbico sobre Mg, Zn, Li e 1-propanol. Não houve efeito significativo nas variáveis $\mathrm{Na}, \mathrm{Cu}$ e 2-metil-1-propanol.

Palavras-chave: viticultura, enologia, uva, vinho, podridão, Botrytis cinerea.
\end{abstract}

\section{SUMMARY}

EFFECT OF Botrytis cinerea ON THE COMPOSITION OF GEWÜRZTRAMINER WINE. The aim of this work was to determine the effect of grape gray bunch rot, caused by Botrytis cinerea, on the composition of Gewürztraminer (Vitis vinifera L.) wine. The treatments consisted of increasing percentages (in weight) of grape gray bunch rot, i.e., 0, 2.5, 5, 10, 15, and 20\%. The experiment underwent six treatments and four replications. The variables evaluated were density, alcohol, total and volatile acidity, dry extract, reduced dry extract, reducing sugars, alcohol in weight/reduced dry extract ratio, ashes, alcalinity of ashes, color (I 420), total polyphenols (I 280), total N, glycerol, gluconic acid, minerals (P, K, Ca, Mg, $\mathrm{Na}, \mathrm{Mn}, \mathrm{Fe}, \mathrm{Cu}, \mathrm{Zn}, \mathrm{Rb}$, Li), volatile compounds (ethanal, ethyl acetate, methanol, propanol-1, methyl-2-propanol-1, methyl-2-buthanol-1, and methyl-3-buthanol-1). Results showed that there was a significant linear and positive effect between gray bunch rot and the following variables: density, total and volatile acidity, dry extract, reduced dry extract, reducing sugars, ashes, alkalinity of ashes, color (I 420), total polyphenols (I 280), gluconic acid, P, K, Ca, Mn, Fe, Rb, ethanal, and ethyl acetate; there was a significant linear and negative effect on alcohol, alcohol in weight/reduced dry extract ratio, methyl-2-buthanol-1, and methyl-3-buthanol-1; a quadratic effect on total N, glycerol, and methanol; and a cubic effect on Mg, Zn, Li, and propanol-1. There was no significant effect on $\mathrm{Na}, \mathrm{Cu}$, and methyl-2-propanol-1.

Keywords: viticulture, enology, grape, wine, gray bunch rot, Botrytis cinerea.

\section{1 - INTRODUÇÃO}

A podridão cinzenta da uva é causada pelo fungo Botrytis cinerea. Há vários fatores que propiciam a infecção e o desenvolvimento desse patógeno, destacando-se a susceptibilidade da cv. Gewürztraminer, precipitação pluviométrica elevada e alta umidade relativa do ar, as quais propiciam a formação de um microclima favorável à infecção da uva pelo patógeno. Altos teores de matéria orgânica no solo e utilização de porta-enxertos vigorosos também contribuem

\footnotetext{
${ }^{1}$ Recebido para publicação em 24/1/2005. Aceito para publicação em 6/7/2006 (001469)

${ }^{2}$ Centro Federal de Educação Tecnológica de Bento Gonçalves,

Av. Osvaldo Aranha, 540, C. P. 130, CEP 95700, Bento Gonçalves (RS),

E-mail:cgpp@cefetbg.gov.br

${ }^{3}$ Embrapa Uva e Vinho, Rua Livramento, 515, C. P. 130 ,

CEP 95700-000, Bento Gonçalves (RS),

E-mails:rizzon@cnpuv.embrapa.br,miele@cnpuv.embrapa.br

${ }^{4}$ Instituto de Ciências e Tecnologia de Alimentos,

Universidade Federal do Rio Grande do Sul,

Av. Bento Gonçalves, 9500, C. P. 15.090,

CEP 91540-000, Porto Alegre (RS),

E-mail:mazayub@ufrgs.br

* A quem a correspondência deve ser enviada
}

para o desenvolvimento deste fungo. Mas solos com estrutura física que favoreçam uma boa drenagem reduzem a incidência de Botrytis cinerea na uva [17].

A podridão cinzenta da uva reduz a produtividade do vinhedo e afeta a qualidade da uva e do vinho, pois diminui o teor de açúcar do mosto, aumenta a acidez volátil e o torna mais vulnerável à oxidação [6, 9]. Além disso, a uva é colhida antes de atingir seu potencial de açúcar o que leva a uma chaptalização mais intensa do mosto. A principal causa de alteração da uva e do vinho é devida à atividade enzimática de Botrytis cinerea, onde a sua enzima específica, a lacase, atua sobre todos os constituintes oxidáveis da uva. Embora alguns desses problemas sejam conhecidos no meio enológico, as suas conseqüências na composição química do vinho Gewürztraminer ainda não foram estudadas na Serra Gaúcha.

\section{2 - MATERIAL E MÉTODOS}

A uva Gewürztraminer utilizada no experimento foi coletada em um vinhedo conduzido no sistema latada, e os fatores climáticos da safra foram favoráveis ao desenvolvimento da podridão cinzenta da uva. 
Por ocasião da colheita, foram separados dois grupos de uva: um, formado por uva sadia e outro, por uva com podridão. Pesaram-se uvas sadias e com podridão de maneira que se obtivessem parcelas com $0 ; 2,5 ; 5 ; 10 ; 15$; e $20 \%$ de podridão. Essas parcelas foram repetidas quatro vezes. Inicialmente separou-se a ráquis da uva, que foi posteriormente esmagada.

O mosto obtido foi colocado em recipiente de vidro de $20 \mathrm{~L}$ de capacidade, onde foram adicionados $50 \mathrm{mg} / \mathrm{L} \mathrm{de}$ $\mathrm{SO}_{2}$. A seguir, a fim de clarificá-lo, foram transferidos para uma câmara fria a $5{ }^{\circ} \mathrm{C}$ durante $10 \mathrm{~h}$. O mosto clarificado e separado das borras por meio de sifonagem foi colocado em uma sala com temperatura controlada de $20{ }^{\circ} \mathrm{C}$ e lhe foi adicionado 0,20 g/L de levedura seca ativa Saccharomyces cerevisiae. Uma vez finalizada a fermentação alcoólica, o vinho foi resfriado a $-3{ }^{\circ} \mathrm{C}$ por um período de 10 dias e filtrado. Antes do engarrafamento, foram aplicados mais $50 \mathrm{mg} / \mathrm{L} \mathrm{de} \mathrm{SO}_{2}$.

As variáveis densidade, álcool, acidez total, acidez volátil, extrato seco, extrato seco reduzido, açúcares redutores, relação álcool em peso/extrato seco reduzido, cinzas e alcalinidade das cinzas, foram analisadas pela metodologia descrita por AMERINE \& OUGH [1], enquanto o N total foi determinado pelo método de micro-Kjeldahl [18].

O índice de cor e os polifenóis totais foram medidos num espectrofotômetro UV/VIS a $420 \mathrm{~nm}$ e a $280 \mathrm{~nm}$, respectivamente (AMERINE \& OUGH, 1976) [1].

O ácido glicônico foi analisado pelo método enzimático [4], sendo o resultado da reação enzimática medido a $520 \mathrm{~nm}$.

Os compostos voláteis (etanal, acetato de etila, metanol, 1-propanol, 2-metil-1-propanol, 2-metil-1-butanol e 3-metil1-butanol) foram determinados por cromatografia gasosa. Foi utilizado um aparelho marca Instrumentos Científicos (CG), modelo 3537-D equipado com detetor de ionização de chama e coluna de vidro de $3,2 \mathrm{~m}$ de comprimento e $1 / 8$ " de diâmetro interno. A fase estacionária foi constituída de Carbowax 600 a 5\% mais Hallcomid M-18 OL a $1 \%$ e o suporte foi Chromosorb W de 60-80 mesh. A amostra de vinho $(3 \mu \mathrm{L})$ foi injetada diretamente no aparelho após ter recebido $10 \%$ do volume de uma solução de 4-metil-2-pentanol a $1 \mathrm{~g} / \mathrm{L}$ como padrão interno [3].

O P foi determinado por colorimetria usando molibdato de amônio; o $\mathrm{Ca}, \mathrm{Mg}, \mathrm{Mn}$, Fe e $\mathrm{Zn}$ foram analisados por espectrofotometria de absorção atômica; enquanto que o K, $\mathrm{Na}, \mathrm{Rb}$ e Li, por emissão de chama [11].

Os dados observados foram submetidos à análise de regressão polinomial.

\section{3 - RESULTADOS E DISCUSSÃO}

A podridão cinzenta da uva teve efeito significativo na maior parte das variáveis do vinho Gewürztraminer (Tabelas 1, 2 e 3), exceção ao $\mathrm{Na}$ e $\mathrm{Cu}$ (Tabela 2) e ao 2-metil-1-propanol (Tabela 3). Entretanto, as variáveis não responderam da mesma forma às crescentes concentrações da podridão cinzenta da uva.

Foi constatado efeito significativo linear e positivo em relação à densidade, acidez total e volátil, extrato seco, extrato seco reduzido, açúcares redutores, cinzas, alcalinidade das cinzas, índice de cor (I 420), polifenóis totais (I 280), ácido glicônico, P, K, Ca, Mn, Fe, Rb, etanal e acetato de etila; efeito significativo linear negativo para o álcool, relação álcool em peso/extrato seco reduzido, 2-metil-1-butanol e 3-metil-1-butanol; efeito quadrático para o $\mathrm{N}$ total, glicerol e metanol; e efeito cúbico para o $\mathrm{Mg}, \mathrm{Zn}$, Li e 1-propanol. Contudo, não houve efeito significativo nas variáveis $\mathrm{Na}, \mathrm{Cu}$ e 2-metil-1-propanol.

A podridão cinzenta da uva aumentou a densidade do vinho provavelmente devido à presença de maiores quantidades de componentes, como por exemplo o açúcar residual. Paralelamente, há liberação de substâncias tóxicas pela Botrytis cinerea, o que dificulta a transformação da glicose e da frutose pelas leveduras. Com a elevação da densidade, ocorreu a diminuição do teor alcoólico do vinho pois a den-

TABELA 1 - Regressão polinomial entre as variáveis clássicas do vinho Gewürztraminer e a podridão cinzenta da uva.

\begin{tabular}{llll}
\hline \multicolumn{1}{c}{ Variável } & \multicolumn{1}{c}{ Equação de regressão } & $\mathbf{R}^{\mathbf{2}}$ \\
\hline Densidade $20 / 20^{\circ} \mathrm{C}(\mathrm{g} / \mathrm{mL})$ & $\mathrm{Y}=0,9960+0,00021 \mathrm{~F}$ & 0,00001 & 0,9630 \\
Álcool $(\% \mathrm{v} / \mathrm{v}) 2{ }^{\circ} \mathrm{C}$ & $\mathrm{Y}=8,74-0,08581 \mathrm{X}$ & 0,00001 & 0,9676 \\
Acidez total $(\mathrm{meq} / \mathrm{L})$ & $\mathrm{Y}=117,4+1,45684 \mathrm{X}$ & 0,00001 & 0,9615 \\
Acidez volátil $(\mathrm{meq} / \mathrm{L})$ & $\mathrm{Y}=4,5+1,61631 \mathrm{X}$ & 0,00001 & 0,9690 \\
Extrato seco $(\mathrm{g} / \mathrm{L})$ & $\mathrm{Y}=19,45+0,12926 \mathrm{X}$ & 0,00001 & 0,7575 \\
Extrato seco reduzido $(\mathrm{g} / \mathrm{L})$ & $\mathrm{Y}=19,15+0,08733 \mathrm{X}$ & 0,00001 & 0,6975 \\
Açúcares redutores $(\mathrm{g} / \mathrm{L})$ & $\mathrm{Y}=1,33+0,04192 \mathrm{X}$ & 0,00001 & 0,8464 \\
Relação álcool em peso/ Extrato seco reduzido & $\mathrm{Y}=3,65-0,04865 \mathrm{X}$ & 0,00001 & 0,9340 \\
Cinzas $(\mathrm{g} / \mathrm{L})$ & $\mathrm{Y}=1,62+0,01531 \mathrm{X}$ & 0,00223 & 0,6115 \\
Alcalinidade das cinzas $(\mathrm{mg} / \mathrm{L})$ & $\mathrm{Y}=14,72+0,22021 \mathrm{X}$ & 0,00002 & 0,9184 \\
Índice de cor $(\mathrm{I} 420)$ & $\mathrm{Y}=0,088+0,00355 \mathrm{X}$ & 0,00001 & 0,7729 \\
Polifenóis totais $(\mathrm{I} 280)$ & $\mathrm{Y}=6,99+0,17761 \mathrm{X}$ & 0,00001 & 0,8561 \\
Nitrogênio total $(\mathrm{mg} / \mathrm{L})$ & $\mathrm{Y}=152,9+2,553 \mathrm{X}-0,19571 \mathrm{X}^{2}$ & 0,00477 & 0,6136 \\
Glicerol $(\mathrm{g} / \mathrm{L})$ & $\mathrm{Y}=5,90-0,20132 \mathrm{X}+0,008569 \mathrm{X}^{2}$ & 0,00001 & 0,9604 \\
Ácido glicônico $(\mathrm{g} / \mathrm{L})$ & $\mathrm{Y}=2,15+0,13099 \mathrm{X}$ & 0,00001 & 0,8820 \\
\hline
\end{tabular}


TABELA 2 - Regressão polinomial entre os minerais do vinho Gewürztraminer e a podridão cinzenta da uva.

\begin{tabular}{|c|c|c|c|}
\hline Variável & Equação de regressão & $\mathbf{P}>\mathbf{F}$ & $\mathbf{R}^{2}$ \\
\hline $\mathrm{P}(\mathrm{mg} / \mathrm{L})$ & $Y=40,8+0,88579 X$ & 0,00001 & 0,6312 \\
\hline $\mathrm{K}(\mathrm{mg} / \mathrm{L})$ & $Y=739,8+4,52105 X$ & 0,00003 & 0,7042 \\
\hline $\mathrm{Ca}(\mathrm{mg} / \mathrm{L})$ & $Y=51,1+0,89631 X$ & 0,00001 & 0,8717 \\
\hline $\mathrm{Mg}(\mathrm{mg} / \mathrm{L})$ & $Y=42,3-0,5889 X+0,14315 X^{2}-0,00538 X^{3}$ & 0,00002 & 0,8118 \\
\hline $\mathrm{Na}(\mathrm{mg} / \mathrm{L})$ & NS & NS & NS \\
\hline $\mathrm{Mn}(\mathrm{mg} / \mathrm{L})$ & $Y=1,25+0,04105 X$ & 0,00001 & 0,7777 \\
\hline $\mathrm{Fe}(\mathrm{mg} / \mathrm{L})$ & $Y=0,19+0,039579 X$ & 0,00001 & 0,9037 \\
\hline $\mathrm{Cu}(\mathrm{mg} / \mathrm{L})$ & NS & NS & NS \\
\hline $\mathrm{Zn}(\mathrm{mg} / \mathrm{L})$ & $Y=1,29-0,2382 X+0,02731 X^{2}-0,000836 X^{3}$ & 0,00082 & 0,9146 \\
\hline $\mathrm{Rb}(\mathrm{mg} / \mathrm{L})$ & $Y=4,81+0,005337 X$ & 0,00001 & 0,7201 \\
\hline $\mathrm{Li}(\mu \mathrm{g} / \mathrm{L})$ & $Y=1,68-0,0556 X+0,01753 X^{2}-0,000629 X^{3}$ & 0,00001 & 0,7424 \\
\hline
\end{tabular}

TABELA 3 - Regressão polinomial entre os compostos voláteis do vinho Gewürztraminer e a podridão cinzenta da uva.

\begin{tabular}{|c|c|c|c|}
\hline Variável & Equação de regressão & $P>F$ & $\mathbf{R}^{2}$ \\
\hline Etanal (mg/L) & $Y=41,1+0,73284 X$ & 0,00051 & 0,9173 \\
\hline Acetato de etila (mg/L) & $Y=39,8+9,64263 X$ & 0,00001 & 0,9533 \\
\hline Metanol (mg/L) & $Y=35,5+1,6817 X+0,05423 X^{2}$ & 0,00001 & 0,9586 \\
\hline 1-Propanol (mg/L) & $Y=15,6+0,3716 X-0,07863 X^{2}+0,003160 X^{3}$ & 0,00018 & 0,6922 \\
\hline 2-Metil-1-propanol (mg/L) & NS & NS & NS \\
\hline 2-Metil-1-butanol (mg/L) & $Y=27,6-0,84915 X$ & 0,00001 & 0,7548 \\
\hline 3-Metil-1-butanol (mg/L) & $Y=172,2-5,66010 X$ & 0,00001 & 0,8747 \\
\hline
\end{tabular}

sidade deste álcool é menor que a da água. A diminuição do teor alcoólico do vinho foi devida, principalmente, ao baixo teor de açúcar no mosto em função da podridão. Mostos com baixo teor de açúcar necessitam de chaptalização mais intensa, prática responsável pela diminuição da qualidade do vinho, isto é, vinhos com pouco corpo e menor tipicidade [13]. A redução máxima estimada pela equação polinomial do teor alcoólico devido à podridão da uva foi de $1,72 \% \mathrm{v} / \mathrm{v}$, o que representa uma perda de aproximadamente $1 / 5$ de seu valor, o que é considerável em termos qualitativos e econômicos.

Foi constatado um aumento significativo da acidez total no vinho. Este resultado deveu-se possivelmente à formação dos ácidos glicônico e acético. Conforme FREGONI et al. [7], a acidez total aumentou nas uvas atacadas pela Botrytis cinerea devido à perda de peso das bagas e à formação dos ácidos glicônico e ácido pirúvico. As principais causas do aumento da acidez volátil do vinho estão relacionadas com a qualidade da uva utilizada. Vários microrganismos podem provocar alterações na acidez volátil dos vinhos, destacando-se as bactérias dos gêneros Acetobacter e Gluconobacter, as quais podem agir concomitantemente com o fungo Botrytis cinerea.

O extrato seco e o extrato seco reduzido aumentaram em função do aumento da porcentagem de uvas atacas por Botrytis cinerea. Isto provavelmente ocorreu devido à presença dos ácidos orgânicos, açúcares redutores, polissacarídeos, pectinas e elementos minerais. A maturação deficiente da uva, causada especialmente por motivos climáticos, elevada fertilidade do solo e alta produtividade do vinhedo, é determinante do baixo teor de açúcares dos mostos e, conseqüentemente, do baixo teor de extrato dos vinhos [16]. Com a diminuição do álcool e o aumento do extrato seco reduzido, houve diminuição da relação álcool em peso/extrato seco reduzido. Concentrações mais elevadas de açúcares residuais nos vinhos estão relacionadas com a diminuição do nitrogênio amoniacal disponível para as leveduras como conseqüência da podridão [6].

O aumento no teor das cinzas pode ter sido devido à degradação da película da uva, que favorece a liberação de maior quantidade de elementos minerais ao mosto, uma vez que é a parte da uva que proporcionalmente apresenta maior quantidade destes constituintes. Além disso, a dificuldade de clarificação dos vinhos com maior porcentagem de podridão do cacho, devido aos colóides protetores, mantém em suspensão maior quantidade de minerais que, conseqüentemente, aumentam o teor das cinzas. O aumento da alcalinidade das cinzas pode indicar maior salificação dos ácidos orgânicos nos vinhos com maior porcentagem de podridão. Por outro lado, o teor alcoólico mais elevado obtido com uvas sadias e com menor porcentagem de podridão cinzenta da uva teria favorecido a precipitação do tartarato ácido de potássio e, conseqüentemente, originaria menor alcalinidade das cinzas.

O índice de cor (I 420) aumentou com o aumento da podridão. Valores superiores a 0,080 nos vinhos brancos indicam coloração dourada intensa. Segundo FREGONI et al. [7], o aumento da cor se deve à oxidação das catequinas e epicatequinas. Os polifenóis totais nos vinhos brancos representam a soma dos compostos fenólicos de baixo peso molecular, que são responsáveis pela coloração amarela, tais como as catequinas, as epicatequinas e as flavonas [19]. 
Mesmo que estes componentes não tenham sido determinados individualmente no presente estudo, pressupõe-se que eles são os responsáveis pelo aumento dos polifenóis totais observados.

Os constituintes nitrogenados das uvas, dos mostos e dos vinhos são importantes na vinificação, conservação e estabilização dos vinhos, podendo representar de $5 \%$ a $10 \%$ do extrato seco total e, também, interferem em suas características sensoriais. MENEGUZZO et al. [10] observaram que o $\mathrm{N}$ total do mosto aumentou até uma determinada concentração de podridão cinzenta da uva, diminuindo a seguir. No vinho, registraram a mesma relação quadrática entre o teor de $\mathrm{N}$ total e a concentração de podridão cinzenta da uva, ou seja, os vinhos obtidos de uvas com $0 ; 2,5$; e $5,0 \%$ de podridão tiveram teores mais elevados de $\mathrm{N}$ total e, com proporções mais elevadas de uvas com Botrytis cinerea, a concentração de $\mathrm{N}$ foi diminuindo.

O glicerol é um produto secundário da fermentação alcoólica. O seu teor no vinho está relacionado com a quantidade inicial de açúcar no mosto, com o estado sanitário da uva, a natureza das leveduras e as condições de fermentação (temperatura, acidez, aeração e sulfitação). Quanto ao teor de glicerol, não foram obtidos os resultados esperados, ou seja, este triálcool não aumentou proporcionalmente com o aumento da podridão cinzenta da uva, pois sua presença respondeu a um efeito quadrático. Segundo RIBÉREAU-GAYON [12], uma das características do fungo Botrytis cinerea é formar alguns gramas de glicerol ainda no mosto, mas a maior parcela é formada durante a fermentação alcoólica.

Segundo McCLOSKEY [8], o ácido glicônico pode ser um indicativo da contaminação das uvas, podendo afetar a qualidade organoléptica do vinho. Sua presença indica que as uvas usadas na vinificação foram atacadas por Botrytis cinerea, pois geralmente a concentração deste ácido orgânico é diretamente proporcional à porcentagem de uva com podridão cinzenta. É o caso constatado neste trabalho, em que os resultados detectados de ácido glicônico no vinho Gewürztraminer indicam uma relação linear positiva em função do aumento da podridão do cacho (Tabela 1). O teor de ácido glicônico presente nos vinhos Sauternes variou de 1,3 g/L a 5,9 g/L (RIBÉREAU-GAYON [12]; na Califórnia, de 0 a 3,09 g/L [8]; no vinho Gewürztraminer brasileiro variou de 1,5 g/L a 4,0 g/L segundo a porcentagem de podridão [9]. Teores de ácido glicônico baixos, inferiores a 1,5 g/L, são indicativo de vinhos elaborados com uvas sem problemas de podridão.

O P é um elemento encontrado principalmente na forma de fosfato. Quando seu teor é muito elevado, pode precipitar causando turvação no vinho [1]. A deterioração da película pela podridão favoreceu a liberação do $\mathrm{K}$ para o mosto. Além disso, os polissacarídeos, destacando-se os glucanos, de Botrytis cinerea favorecem a presença deste cátion em maior quantidade em suspensão no vinho, pois funcionam como colóides protetores [13]. O Ca é outro elemento normalmente encontrado nos vinhos, em concentração que varia de 60 a $150 \mathrm{mg} / \mathrm{L}$. Os tratamentos fitossanitários efetuados na videira com calda bordalesa, podem ter se constituído numa fonte deste elemento mineral no vinho. Devido à maior acidez dos vinhos brancos, a qual favorece a dissolução do tartarato de cálcio, geralmente eles possuem maiores concentrações de Ca que os vinhos tintos. Os riscos de precipitação do tartarato de cálcio podem ocorrer quando as concentrações desses elementos são superiores a $80 \mathrm{mg} / \mathrm{L}$ [14]. Em relação ao efeito da podridão da uva no teor de Ca do vinho Gewürztraminer, constatou-se um aumento significativo deste mineral (Tabela 2). Uma vez que o $\mathrm{Ca}$ se encontra em maior quantidade na película [14], a ação dos microrganismos sobre ela favorece a sua liberação no mosto e, conseqüentemente, nos vinhos. Contudo, os teores presentes nos vinhos analisados não são suficientes para causar problemas de turvação.

O Mn é encontrado nos vinhos em teores inferiores a $5 \mathrm{mg} / \mathrm{L}$. Embora sua concentração esteja em função da característica do solo, a vinificação pode contribuir para aumentar seu teor, uma vez que este mineral é encontrado em maior quantidade nas sementes da uva. O emprego de certos produtos fitossanitários para controle das doenças da videira e alguns produtos enológicos podem interferir no teor de Mn do vinho. A pequena variação de Mn constatada neste trabalho pode ter ocorrido pela liberação deste cátion da semente da uva por ação do ataque da podridão [15]. $\mathrm{O}$ Fe é um cátion normalmente encontrado nos vinhos em pequenas quantidades, geralmente inferiores a $7 \mathrm{mg} / \mathrm{L}$. Este mineral está relacionado ao problema de óxido-redução, causando turvações nos vinhos [1]. O ataque da película da uva pelos microrganismos causadores da podridão pode ter favorecido a liberação de maior quantidade de Fe no mosto e no vinho. O Zn é encontrado regularmente nos vinhos em concentrações inferiores a 4,0 mg/L [14]. A incorporação de $\mathrm{Zn}$ aos vinhos pode ter ocorrido devido ao contato de material galvanizado ou produtos fitossanitários aplicados na videira. A resposta de terceiro grau do $\mathrm{Zn}$ à podridão provavelmente foi devida a uma possível contaminação, totalmente independente do fator microbiológico.

Assim como o Li, o Rb tem sido útil para discriminar os vinhos de diferentes regiões vitícolas do mundo. As informações disponíveis atualmente sobre o teor de $\mathrm{Rb}$ nos vinhos são reduzidas, mas sabe-se que este componente está sempre presente em pequenas quantidades, em concentrações geralmente inferiores a $10 \mathrm{mg} / \mathrm{L}$. No entanto, no caso da vinificação em tinto, constatou-se que a concentração deste cátion aumenta com o tempo de maceração da película [15]. O vinho Gewürztraminer elaborado com uvas sadias ou com menor índice de podridão teve maior concentração de $\mathrm{Rb}$ que aqueles elaborados com maiores concentrações de uvas atacadas por Botrytis. Isto ocorreu devido, provavelmente, à maior degradação da película e à presença de colóides protetores, que evitam a precipitação desse cátion nos vinhos elaborados com uvas atacadas por Botrytis cinerea.

Quanto ao efeito da podridão da uva nos teores de Mg, Zn e Li do vinho Gewürztraminer, observou-se um efeito de terceiro grau. A liberação desses minerais para o mosto e 
para o vinho, possivelmente tenha ocorrido em função da degradação da película da uva. Os teores de Mg normalmente encontrados no vinho variam de 50 a $120 \mathrm{mg} / \mathrm{L}$ e podem contribuir para a tipicidade dos vinhos de uma determinada região vitícola [14].

Com relação aos compostos voláteis, o etanal é, quantitativamente, o aldeído mais importante do vinho, pois geralmente é encontrado em teores próximos a $75 \mathrm{mg} / \mathrm{L}$. Sua formação, por ocasião da fermentação alcóolica, depende da natureza das leveduras, $\mathrm{pH}$, substâncias nitrogenadas e temperatura, mas sobretudo da quantidade de $\mathrm{SO}_{2}$ aplicada no mosto [2]. A variação encontrada neste trabalho, entretanto, não pode ser atribuída às doses de $\mathrm{SO}_{2}$, uma vez que a quantidade usada foi a mesma em todos os tratamentos. No entanto, o grau de podridão interfere diretamente na atividade fermentativa do mosto, dificultando a redução do etanal à álcool etílico.

$\mathrm{O}$ acetato de etila contribui, juntamente com o ácido acético, para o avinagramento do vinho. Por isso, teores baixos de acetato de etila estão sempre relacionados com vinhos de qualidade. Além do fungo Botrytis cinerea, as uvas provavelmente também foram atacadas por bactérias acéticas que favoreceram a formação da acidez volátil, como foi visto anteriormente, e do acetato de etila. Além disso, a esterificação enzimática do ácido acético pode ter sido favorecida nos vinhos elaborados com uvas com maior intensidade de podridão [5].

A presença de metanol nos vinhos está relacionada à hidrólise das pectinas que, por sua vez, depende de uma maior ou menor maceração da parte sólida da uva, especialmente da película. A fermentação alcoólica não conduz à formação de metanol nos vinhos [3, 14]. Os agentes causadores da podridão modificam a composição da película da uva, liberam maior quantidade de pectina e favorecem a ação enzimática. A participação da podridão cinzenta da uva no teor de metanol do vinho Gewürztraminer é semelhante à que foi observada na maceração pelicular e na vinificação de mostos de uvas sobremaduras [3]. De outra parte, RIBÉREAU-GAYON [12] observou que o mosto de uva botritizada não apresentava mais pectina que aquele de uva sadia. BERTRAND [3] atribuiu o teor mais elevado de metanol das uvas que passaram do ponto de maturação à sua maior concentração na baga e à maior esterificação das pectinas.

São designados álcoois superiores os que possuem mais de dois átomos de carbono. Eles são considerados compostos secundários da fermentação alcoólica, resultantes do metabolismo das substâncias nitrogenadas do mosto pela ação das leveduras [3]. Os teores de 2-metil-1-butanol e 3-metil-1-butanol sofreram uma diminuição acentuada em conseqüência da podridão da uva, pois são formados durante todo o processo fermentativo. Portanto, o teor final destes dois álcoois superiores no vinho é proporcional à quantidade de etanol formado.

O 1-propanol, ao contrário dos demais álcoois superiores analisados, é formado pelas leveduras preferencialmente no início da fermentação alcoólica quando há disponibilidade de maior quantidade de substâncias nitrogenadas [3]. O 2-metil-1-propanol é mais influenciado pelos fatores relacionados à clarificação do mosto, sendo que vinhos obtidos de mostos clarificados possuem teores mais baixos deste álcool superior [3, 16]. Uma vez que os mostos foram clarificados da mesma maneira, o efeito da podridão cinzenta da uva não foi significativo na concentração do 2-metil-1-propanol.

\section{4 - CONCLUSÕES}

A vinificação da uva Gewürztraminer com diferentes níveis de podridão cinzenta, causada pelo fungo Botrytis cinerea, alterou os teores da maior parte das variáveis avaliadas. O efeito deste fungo geralmente foi linear, positivo ou negativo. Entretanto, algumas variáveis responderam à sua ação com equações de primeiro e de segundo graus; outras, foram diretamente afetadas pela ação deste patógeno na uva, como é o caso da densidade e do álcool, de certos elementos minerais e de compostos voláteis. Entretanto, a podridão cinzenta da uva, por meio de seu agente causal, interferiu indiretamente na composição e na qualidade do vinho, pois provavelmente criou condições para a ação de bactérias acidificantes se desenvolverem e aumentarem a acidez volátil e o acetato de etila do vinho. Além disso, constatou-se aumento do índice de cor (I 420), provavelmente causado por enzimas oxidativas presentes no fungo. Outras modificações, especialmente a dos álcoois superiores, foram causadas pela interferência na atividade fermentativa. Ressalta-se, entretanto, que algumas variáveis, como o glicerol e o ácido glicônico, não apresentaram a evolução esperada em conseqüência da ação do fungo Botrytis cinerea.

\section{5 - REFERÊNCIAS BIBLIOGRÁFICAS}

[1] AMERINE, M. A.; OUGH, C. S. Análisis de vinos y mostos. Zaragoza: Acribia, 1976. 158p.

[2] BARO, J. A. L.; QUIROS CARRASCO, J. M. Les conditions de formation des aldéhydes dans les vins: relation et importance en rapport avec les phénomènes d'oxidation et les caractéristiques organoleptiques. Bulletin de l'OIV, v. 50, n. 554, p. 253-267, 1977.

[3] BERTRAND, A. Recherches sur l'analyse des vins par chromatographie en phase gazeuse. Talence, 1975, 291 p. Tese (Doutorado em Enologia) - Institut d'Oenologie, Université de Bordeaux II.

[4] BOEHRINGER. Methods of enzymatic food analysis. Mannheim: Boheringer, 1984. p. 79.

[5] DAUDT, C. E.; OUGH, C. S. Variations in some volatile acetate esters formed during grape juice fermentation. Effects of fermentation temperature, $\mathrm{SO}_{2}$, yeast strain and grape variety. American Journal of Enology and Viticulture, v. 24, n. 3, p. 130-135, 1973.

[6] DUBOURDIEU, D. Recherches sur les polysaccharides sécretés par Botrytis cinerea dans la baie de raisin. Talence, 1982, 251 p. Tese (Doutorado em Enologia) - Institut d'Oenologie, Université de Bordeaux II.

[7] FREGONI, M.; IACONO, F.; ZAMBONI, M. Influence du Botrytis cinerea sur les caractéristiques physico-chimiques du raisin. Bulletin de l'OIV, v. 59, n. 667-668, p. 995-1013, 1986. 
[8] McCLOSKEY, L. P. Gluconic acid in California wines. American Journal of Enology and Viticulture, v. 25, n. 4, p. 198-201, 1974.

[9] MENEGUZZO, J. Influência da podridão da uva na composição química e na qualidade do vinho Gewürztraminer. Porto Alegre, 1996, 121 p. Dissertação (Mestrado em Microbiologia Agrícola e do Ambiente) - Instituto de Ciências e Tecnologia dos Alimentos, Universidade Federal do Rio Grande do Sul.

[10] MENEGuZZO, J.; RIZZON, L. A.; MIELE, A.; AYUB, M. A. Z. Efeito da podridão do cacho na composição do mosto de Vitis vinifera cv. Gewürztraminer. Fitopatologia Brasileira, v. 24, n. 1, p. 45-48, 1999.

[11] PERKIN-ELMER. Analytical methods for atomic absorption spectrophotometry. Singapura: Perkin-Elmer, 2000. 300p.

[12] RIBÉREAU-GAYON, P. Botrytis: advantages and disadvantages for producing quality wines. SECOND INTERNATIONAL COOL CLIMATE VITICULTURE AND OENOLOGY SYMPOSIUM, AUCKLAND, New Zeland, 1988. Anais do...Auckland, New Zeland, 1988, 319-323p.

[13] RIBÉREAU-GAYON, P.; DUBOURDIEU, D.; DONÈCHE, B.; LONVAUD, A.; Traité d'Oenologie 1. Microbiologie du vin, vinifications. Paris: Dunod, 1998. v. 1. $617 \mathrm{p}$.
[14] RIBÉREAU-GAYON, P.; GLORIES, Y.; MAUJEN, A.; DUBOURDIEU, D. Traité d'Oenologie 2. Chimie du vin, stabilisation et traitements. Paris: Dunod, 1998. v. 2.519 p.

[15] RIZZON, L. A. Incidence de la macération sur la composition chimique des vins. Talence, 1985, $225 \mathrm{p}$. Tese (Doutorado em Viticultura e Enologia) - Institut d'Oenologie, Université de Bordeaux II.

[16] RIZZON, L. A.; MENEGUZZO, J. Influência da clarificação do mosto na composição e na qualidade do vinho branco. Boletim do Centro de Pesquisa e Processamento de Alimentos, v. 14, n. 2, p. 171-180, 1996.

[17] SEGUIN, G.; COMPAGNON, J. Une cause du développement de la pourriture grise sur les sols gravelo-sableux $\mathrm{du}$ vignoble bordelais. Connaissance de la Vigne et du Vin, v. 2, n. 2, p. 202-214, 1970.

[18] TEDESCO, M. J.; VOLKWEISS, J. J.; BOHNEN, H. Análise de solo e plantas e outros materiais. Porto Alegre: Departamento de Solos, Faculdade de Agronomia, Universidade Federal do Rio Grande do Sul, 1995. (Boletim Técnico, 5). 174p.

[19] VOYATZIS, I. Recherches sur les composés phénoliques des vins blancs: Interprétation de la couleur. Talence, 1984, 225 p. Tese (Doutorado em Viticultura e Enologia) - Institut d’Oenologie, Université de Bordeaux II. 